
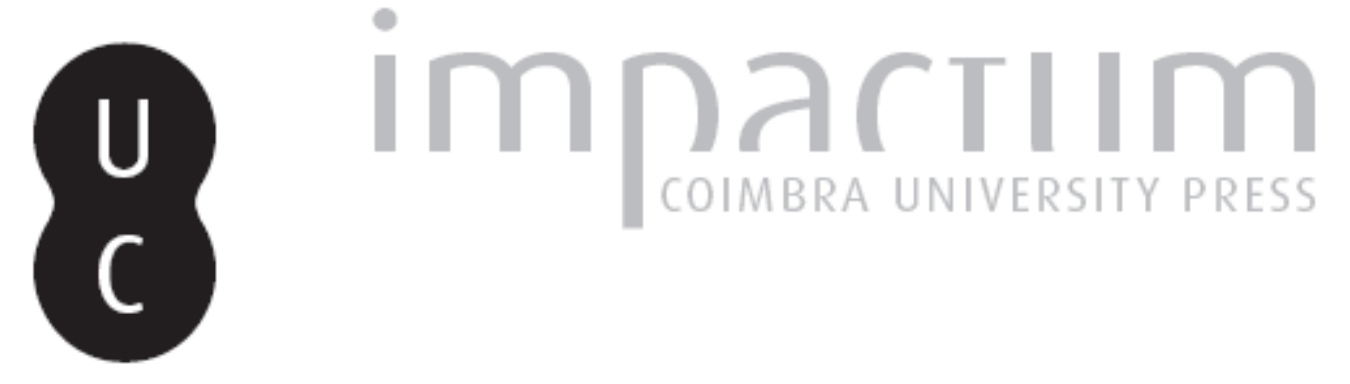

\title{
Las concesiones de Enrique II y Juan I a Don Pedro Ruiz Sarmiento, Adelantado Mayor de Galicia
}

Autor(es): $\quad$ Fernández Suárez, Gonzalo Francisco Publicado por: $\quad \begin{aligned} & \text { Instituto de História Económica e Social, Faculdade de Letras da } \\ & \text { Universidade de Coimbra }\end{aligned}$

URL

persistente:

DOI: $\quad$ DOI:http://dx.doi.org/10.14195/0870-4147_40_15

Accessed : $\quad$ 26-Apr-2023 08:36:53

A navegação consulta e descarregamento dos títulos inseridos nas Bibliotecas Digitais UC Digitalis, UC Pombalina e UC Impactum, pressupõem a aceitação plena e sem reservas dos Termos e Condições de Uso destas Bibliotecas Digitais, disponíveis em https://digitalis.uc.pt/pt-pt/termos.

Conforme exposto nos referidos Termos e Condições de Uso, o descarregamento de títulos de acesso restrito requer uma licença válida de autorização devendo o utilizador aceder ao(s) documento(s) a partir de um endereço de IP da instituição detentora da supramencionada licença.

Ao utilizador é apenas permitido o descarregamento para uso pessoal, pelo que o emprego do(s) título(s) descarregado(s) para outro fim, designadamente comercial, carece de autorização do respetivo autor ou editor da obra.

Na medida em que todas as obras da UC Digitalis se encontram protegidas pelo Código do Direito de Autor e Direitos Conexos e demais legislação aplicável, toda a cópia, parcial ou total, deste documento, nos casos em que é legalmente admitida, deverá conter ou fazer-se acompanhar por este aviso.

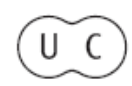



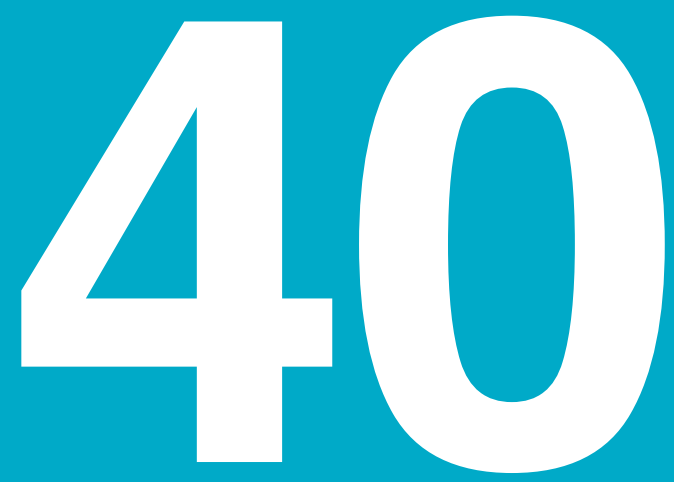

\section{Revista Portuguesa de História}

Faculdade de Letras da Universidade de Coimbra Instituto de História Económica e Social

Coimbra 08/09 


\title{
Las Concesiones de Enrique II y Juan I a Don Pedro Ruiz Sarmiento, Adelantado Mayor de Galicia
}

\author{
GonZalo Francisco Fernández SuÁreZ \\ Universidad de Santiago de Compostela
}

Don Pedro Ruiz Sarmiento, Adelantado Mayor de Galicia, es un claro ejemplo del ascenso de un personaje en la escala nobiliar de la Galicia bajomedieval. $\mathrm{Su}$ adhesión a la causa trastamarista desde el principio de la guerra civil castellana (1366-1369) y la ayuda prestada a la nueva dinastía ${ }^{1}$ constituyen los factores clave que explican su posterior promoción. Por lo tanto, la formación de su patrimonio vino determinada por las donaciones regias que constituirían la base fundamental de sus posesiones y las de sus descendientes. Galicia fue el lugar elegido pues era donde había realizado sus servicios más destacados y además poseía un título que lo vinculaba a este reino. Dentro de esta carrera de gratificaciones pueden distinguirse dos etapas fundamentales.

Una primera etapa se extiende de 1372 a 1375. Son las llamadas mercedes enriqueñas, es decir, las gratificaciones que en forma de villas, rentas, cargos etc. Enrique de Trastámara distribuyó entre todos aquellos que habían contribuído a su victoria. Pero en el caso que nos ocupa, en su totalidad se encuentran fuera

${ }^{1}$ Detalles sobre estos aspectos en FERNÁNDEZ SUÁREZ, GONZALO FRANCISCO: La nobleza gallega entre los siglos XIV-XV: los Sarmiento, condes de Ribadavia. Santiago de Compostela, 2002, pp. 79-82. 
del período en el que se produce el mayor número de concesiones que se sitúa entre 1369 y las Cortes de Montiel de $1371^{2}$. La explicación de esto hay que buscarla en el hecho de que la misión principal de Don Pedro a Enrique II tuvo lugar en 1371 al derrotar junto con Pedro Manrique, Adelantado Mayor de Castilla, a Don Fernando de Castro en la batalla de Porto de Bois y, unido a esto, el interés de este monarca, según Julio Valdeón, por consolidar económicamente a esta nobleza de segunda fila de la que formaba parte nuestro personaje, mientras que la de parientes se debilitaba ${ }^{3}$. Haciendo constar de entrada los "muchos serviçios e buenos que fesiestes e nos fasedes cada dia", Enrique II hizo entrega a Don Pedro Ruiz Sarmiento del Burgo do Faro en $1372^{4}$. Tres años después, en 1375, el mismo monarca le otorgaba una nueva merced en la que se incluían las villas de Santa Marta de Ortigueira y Ribadavia ${ }^{5}$. Ángel Rodríguez González y José García Oro disienten a la hora de señalar la razón o razones que llevaron a Don Enrique a entregar estas poblaciones a Sarmiento. Así, por ejemplo, el primero de estos autores interpreta el paso de Ribadavia de la Corona a manos señoriales como un castigo aplicado por el Trastámara a una población que durante la guerra civil se había mantenido fiel a la causa petrista ${ }^{6}$. Diametralmente opuesta es la opinión de García Oro para quien la cesión de Ribadavia obedece fundamentalmente a motivos de tipo económico y geoestratégico. Para este autor, la riqueza vitícola de esta villa, su situación como nudo de comunicaciones que enlazan la costa gallega con Castilla y su cercanía a la frontera portuguesa serían las auténticas causas ${ }^{7}$.

2 VALDEÓN BARUQUE, JULIO: Enrique II: la guerra civil y la consolidación del régimen (1366-1371). Valladolid, 1966, p. 286.

3 Idem: "Notas sobre las mercedes de Enrique II de Castilla." Hispania. Madrid, 108 (1968), p. 40.

${ }^{4}$ Carta de privilegio y confirmación datada en Agosto de 1379. Arquivo Histórico Universitario de Santiago, Fondo Medinaceli, Sección Ribadavia, Microfilm 302 legajo 1 número 2 (A partir de aquí citaremos este fondo documental con las siguientes siglas A.H.U.S., Medinaceli, Ribadavia, M. 302 leg. 1 n. ${ }^{\circ}$ 2).

5 Carta de privilegio fechada en Burgos el 27 de Agosto de 1379. A.H.U.S., Medinaceli, Ribadavia, M. 302 leg. 1 n.o 2.

6 RODRÍGUEZ GONZÁLEZ, ÁNGEL: "Pedro I de Castilla y Galicia." Boletín de la Universidad de Santiago de Compostela. Santiago de Compostela, 64 (1956), p. 265.

7 GARCÍA ORO, JOSÉ: La nobleza gallega en la Baja Edad Media: las casas nobles y sus relaciones estamentales. Santiago de Compostela, 1977, pp. 76-77. Sobre la riqueza vitícola de Ribadavia, vid. a HUETZ DE LEMPS, ALAIN: Vignobles et vins du Nord-Ouest de l'Espagne. Bordeaux, 1967. El carácter de Ribadavia como centro rector de las comunicaciones ha sido puesto de relieve por Elisa Ferreira con estas palabras: "Valle vitícola, exportador de vino desde la Alta Edad Media, todos sus caminos principales tienden hacia el exterior. De relieve quebrado y densamente poblado, hay una compleja red de caminos secundarios que comunican unas aldeas 
Lo mismo cabería pensar del Burgo do Faro $^{8}$ y de Santa Marta de Ortigueira desde cuya situación en la costa norte de Galicia funcionarían como auténticas atalayas de vigilancia del Atlántico. De este modo, Enrique II no sólo trataba de gratificar a Sarmiento, sino también de implicarlo en la defensa del reino mediante la concesión de unas villas estratégicamente situadas ${ }^{9}$. Por lo demás, la entrega de estos lugares al Adelantado de Galicia responde al típico modelo de las mercedes enriqueñas en las que, en líneas generales, se dotaba a sus titulares de la plenitud jurisdiccional ("mero mixto imperio" ${ }^{10}$ ) y se les cedía la percepción de ciertos tributos ${ }^{11}$. Sin embargo, la entrega del Burgo do Faro, Ribadavia y Santa Marta de Ortigueira a Sarmiento no estuvo exenta de ciertas limitaciones. Así, por ejemplo, en el caso del Burgo do Faro la única reserva que se hace, se refiere a la enajenación de este lugar a favor de religiosos y extranjeros sin autorización real. Por lo demás, no se añade nada nuevo, tan sólo se cambia de titular ya que los servicios que sus vecinos satisfacían a su anterior señor, Don Fernando de Castro, será lo que ahora deberán entregar a su nuevo señor. Por el contrario, mayores reservas estableció Enrique II en relación a Ribadavia y Santa Marta de Ortigueira. A la restricción ya apuntada en el caso anterior, se sumaban otras que insistían en la permanencia de la explotación de los yacimientos mineros en manos de la Corona, la recaudación por ésta de ciertos tributos como los servicios, alcabalas y tercias y la posible intervención real en estas villas merced a la reserva del señorío real:

con otras. El río Arnoia sirve de eje central, y paralelos a él van los caminos que conducen a la costa por las montañas. En la confluencia con el Miño está la villa de Ribadavia, capital de la comarca y nudo de comunicaciones con el mar, la montaña, la comarca de la Arnoia y el Bajo Miño.” Vid. desta autora Los caminos medievales de Galicia. Ourense, 1988, p. 147.

8 Este lugar se corresponde con la actual parroquia de Santiago do Burgo en el municipio coruñés de Culleredo. Vid. Gran Enciclopedia Gallega. Santiago de Compostela, 1974, t. IV, p. 82 .

9 Este carácter estratégico de muchas de las concesiones del primer monarca Trastámara, en especial, las realizadas a favor de ciertos caudillos militares, ha sido puesto de relieve por Julio Valdeón. Vid. Enrique II...op. cit., p. 281.

${ }^{10}$ Una aproximación a esta particularidad en GRASSOTTI, HILDA: "Novedad y tradición en las donaciones con mero mixto imperio en León y Castilla" En: Homenaje al profesor Juan Torres Fontes. Murcia, 1987, pp. 723-736.

${ }^{11}$ Sobre el contenido de las donaciones despachadas por Enrique II vid. a VALDEÓN BARUQUE, JULIO: "Notas sobre las mercedes..., op. cit." pp. 46-47. 


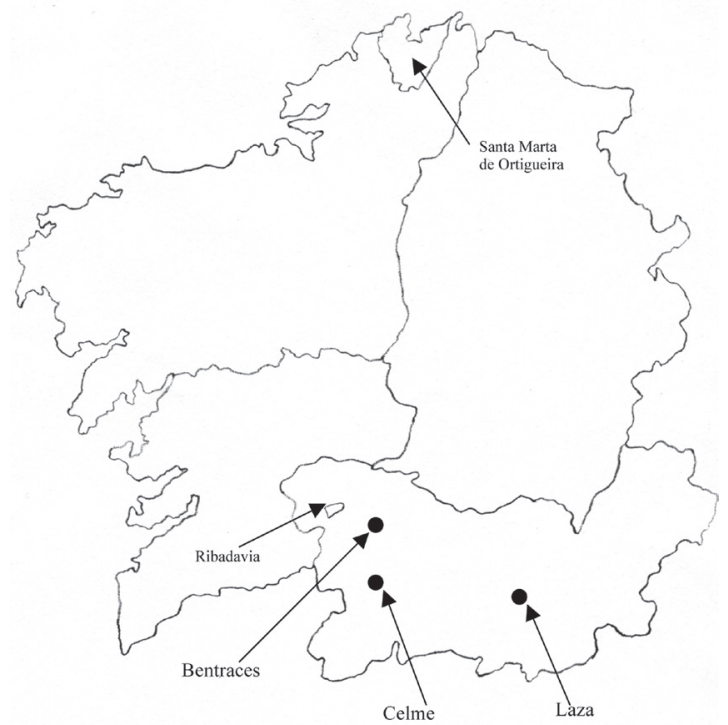

Fig .1 - $1^{\mathrm{a}}$ etapa de mercedes de Enrique II a Don Pedro Ruíz Sarmiento (1372-1375) Mercedes enriqueñas: Burgo do Faro; Ribadavia; Santa Marta de Ortigueira

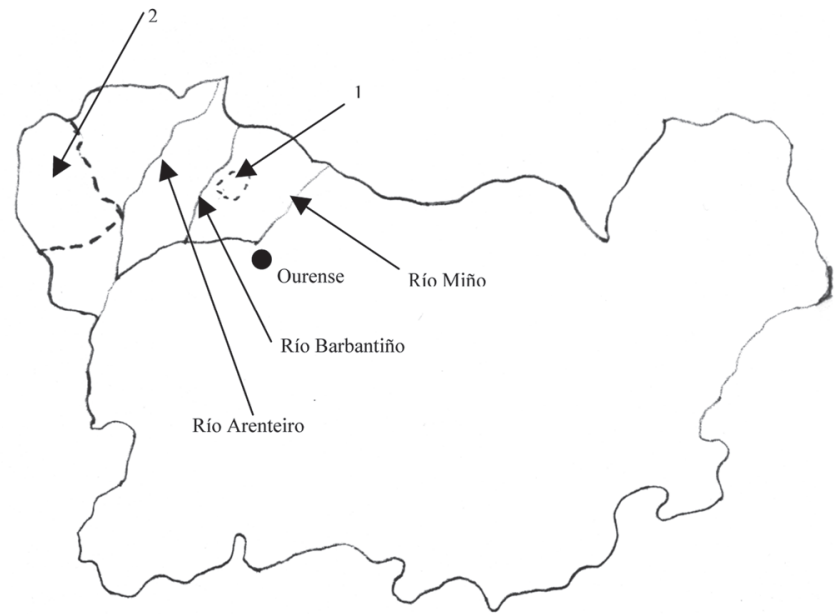

Fig. 2 - $1^{\text {a }}$ etapa de mercedes de Enrique II a Don Pedro Ruíz Sarmiento (1372-1375) Mercedes enriqueñas: 1 - Coto de Anllo; 2 - Tierra de Avión 
“..., dámosvos e fasemos merçed por juro de heredat para agora e [para] sienpre jamás para vos e para vuestros herederos e para los que de vos e dellos venieren de los lugares de Santa Marta de Or[ty]gera e de Ribadavia que a nos pertenesçen con todos su términos e con todos sus vasallos e vesinos de $\mathrm{m}[. .$.$] , montes e pastos e aguras corrientes e estantes e con la$ jurediçión alta e baxa e justiçia çevil e creminal del mero misto ynperio e con todas las rentas e pechos e derechos que a nos pertenesçe e pertenesçer deve en [qualquier] manera en los dichos lugares e en cada uno dellos e en sus términos como dicho es. Pero que retenemos [en] nos e para los reyes que de nos venieren mineras de oro o de plata o de asul sy las ha e serviçios [...] alcavalas e terçias e el señorío real que nos y devemos aver." ${ }^{2}$

En resumen, la cesión que el monarca Trastámara realiza con estas poblaciones no resulta tan onerosa como en un principio pudiera parecer. Primero, porque la monarquía se asegura la explotación de los yacimientos mineros y el cobro de determinados tributos, en especial, aquéllos más sustanciosos. Segundo, porque limita los posibles candidatos a quienes se puede transmitir este patrimonio y, finalmente, unido a lo anterior se establece una cláusula que posibilita la intervención real en estas villas y su posible reversión a la Corona.

Una segunda etapa en la que dividíamos la formación del patrimonio de Don Pedro, se corresponde con los años 1379, momento de inicio del reinado de Juan I, y 1382. Dentro de ésta, puede hacerse, a su vez, una subdivisión en dos momentos. El primero de éstos coincide con el período en el que el futuro monarca aún es infante y como tal ostenta la dignidad de señor de Lara. Por lo tanto, no fue ninguna población de Galicia la escogida para gratificar a Sarmiento sino la villa de Sasamón en tierras burgalesas ${ }^{13}$. Una vez coronado rey, Juan I despacharía una nueva remesa de concesiones a su favor, esta vez, en Galicia. Separadas por escasos días, la tierra de Sobroso ${ }^{14}$ y Avión ${ }^{15}$ junto con el coto de Anllo ${ }^{16}$ fueron pasando una tras otra a manos del Adelantado de Galicia. No se trata de posesiones nuevas para Don Pedro en el caso de la tierra de Avión y el coto de Anllo, sino que, como aclara el mismo monarca,

${ }^{12}$ Carta de privilegio dada en Burgos el 27 de Agosto de 1379. A.H.U.S., Medinaceli, Ribadavia, M. 302 leg. 1 n. 2.

${ }^{13}$ Albalá de donación publicado por SUÁREZ FERNÁNDEZ, LUIS: Historia del reinado de Juan I de Castilla. Madrid, 1982, vol. II, pp. 24-25.

${ }^{14}$ Albalá real incluido en una carta de privilegio otorgada en Burgos el 19 de Agosto de 1379. A.H.U.S., Medinaceli, Ribadavia, M. 302 leg. 1 n. ${ }^{\circ} 2$.

${ }^{15}$ Privilegio real sin fecha. A.H.U.S., Medinaceli, Ribadavia, M. 302 leg. 1 n. ${ }^{\circ} 9$.

${ }^{16}$ Privilegio real despachado el 15 de Diciembre de 1379.A.H.U.S., Medinaceli, Ribadavia, M. 302 leg. 1 n. 12 . 
éste las venía disfrutando desde los días de Enrique II y sólo reclamaba los diplomas acreditativos:

“... por quanto el dicho Rey, mi padre, vos ovo dado e fecho merçet por juro de heredat del coto de Anllo que es en el Reyno de Gallisia en la meryndat que llaman de Orsellon e vos pediestes las cartas [...] que teniades del dicho Rey, mi padre, en esta rason."17

En todas ellas se mantenía la misma restricción: la prohibición de enagenar a favor de religiosos y extranjeros sin licencia real. Pero esta permisividad comenzó a mudar desde fines de 1379. El 15 de diciembre de este año Juan I ponía en manos de Sarmiento la tierra del Ribeiro de Avia. En el correspondiente albalá también se incluían las ya donadas tierra de Avión y coto de Anllo. Esta maniobra del monarca sólo se comprende si echamos una mirada a las restricciones que se establecían:

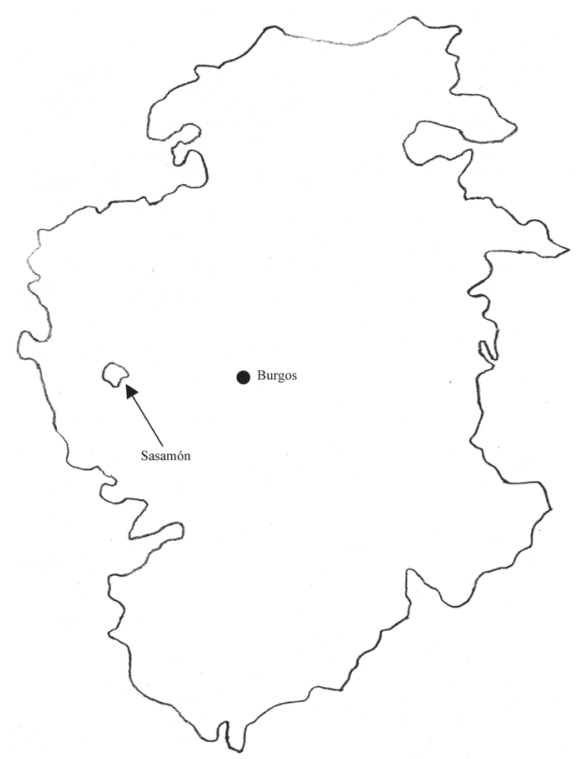

Fig. 3 - Merced del infante Don Juan a Don Pedro Ruíz Sarmiento de la villa de Sasamón (20 de marzo de 1379)

${ }^{17}$ Ibidem. 
“..., pero que tenemos por bien que ninguna destas cosas non podades faser con ome de orden nin de religión nin de fuera de nuestro señorío sin nuestra liçençia e sin nuestro mandado. Pero todavía tenemos por bien e es la nuestra merçed que vos non podades echar nin levar nin echedes nin llevedes en las dichas tierras nin en alguna dellas otros pechos nin pedidos nin otras cosas algunas, salvo aquéllas que echastes e llevastes en tienpo del Rey, nuestro padre, e que usedes con ellos así en esto como en fecho de la justiçia e del mero misto inperio e con todas las otras cosas, segund que usastes en tienpo del dicho Rey, nuestro padre, e non de otra guisa ninguna, ca así es nuestra merçed." 18

Al incluirse en este albalá la tierra de Avión y el coto de Anllo, se establecía con claridad el alcance de las atribuciones jurisdiccionales y fiscales de Don Pedro en ellas y se equiparaban con el Ribeiro de Avia. ¿Un reflejo de la prepotencia que el Adelantado de Galicia estaba demostrando con relación a las encomiendas monásticas y un intento de que estos abusos no se repitieran dentro de su señorío ${ }^{19}$. Verdad o no, lo cierto es que ya meses antes Juan I había dado muestras de su recelo hacia este personaje. Indicio de ello, es que en agosto de 1379 al confirmarle la posesión de la tierra de Sobroso, el monarca añadía nuevos apartados inexistentes en el albalá original. En virtud de ellas, la autoridad real pasaba a ejercer un control más estricto del régimen jurisdiccional y fiscal, reservándose del mismo modo la explotación de los posibles yacimientos mineros:

"Pero tenemos por bien do vos menguaredes la justiçia que nos gela mandemos faser e conplir [...] retenemos para nos e para los reyes que después de nos reynaren en Castiella e en León alcavalas e monedas e terçias e los $[\ldots]$ s, pechos quando los echaremos en los nuestros reynos para los nuestros menesteres e mineras de oro e de plata e de asul e de otro metal si los y oviere." 20

${ }^{18}$ Albalá real despachado el 15 de Diciembre de 1379. A.H.U.S., Medinaceli, Ribadavia, M. 302 leg. 1 n. ${ }^{\circ}$.

${ }^{19}$ Esta faceta de Don Pedro aparece recogida en nuestro trabajo La nobleza gallega... op. cit., pp. 95-101.

${ }^{20}$ Carta de confirmación otorgada el 19 de Agosto de 1379.A.H.U.S., Medinaceli, Ribadavia, M. 302 leg. 1 n. 2 . 


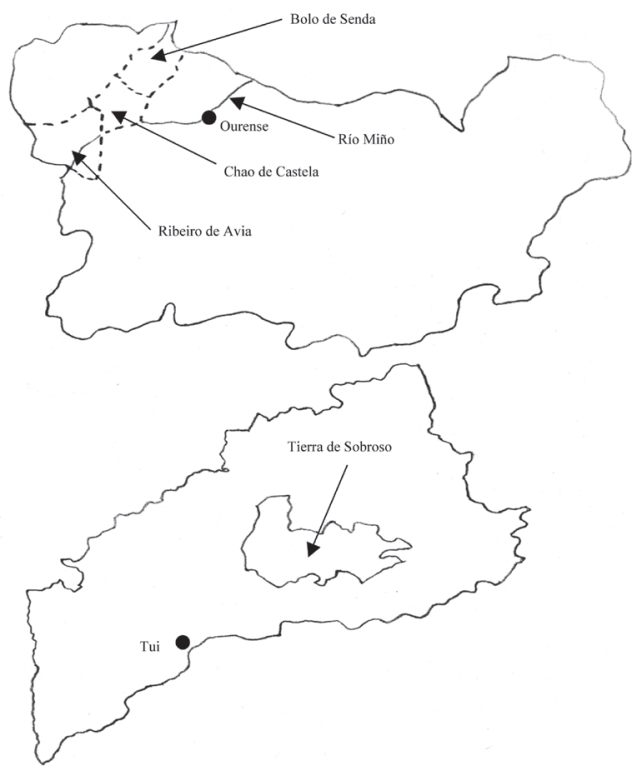

Fig. 4 - Merced de Juan I a Don Pedro Ruíz Sarmiento del Ribeiro de Avia, Chao de Castela, Bolo de Senda y tierra de Sobroso

Finalmente esta carrera de gratificaciones se completaría en 1380 con la entrega a Don Pedro de la tierra de Chao de Castela y el coto de Bolo de Senda ${ }^{21}$ y en 1382 con el poztazgo del puente de Ourense ${ }^{22}$.

El resultado de estas cesiones territoriales es un señorío concentrado en la actual comarca de O Ribeiro con un pequeño apéndice que sobresale hacia la costa atlántica gallega en la tierra de Sobroso.

${ }^{21}$ Albalá real despachado el 5 de Abril de 1380. A.H.U.S., Medinaceli, Ribadavia, M. 302 leg. 1 n.o 2 .

${ }^{22}$ Privilegio real despachado en Segovia el 25 de Febrero de 1382. A.H.U.S., Medinaceli, Ribadavia, M. 302 leg. 1 n.o 2. 

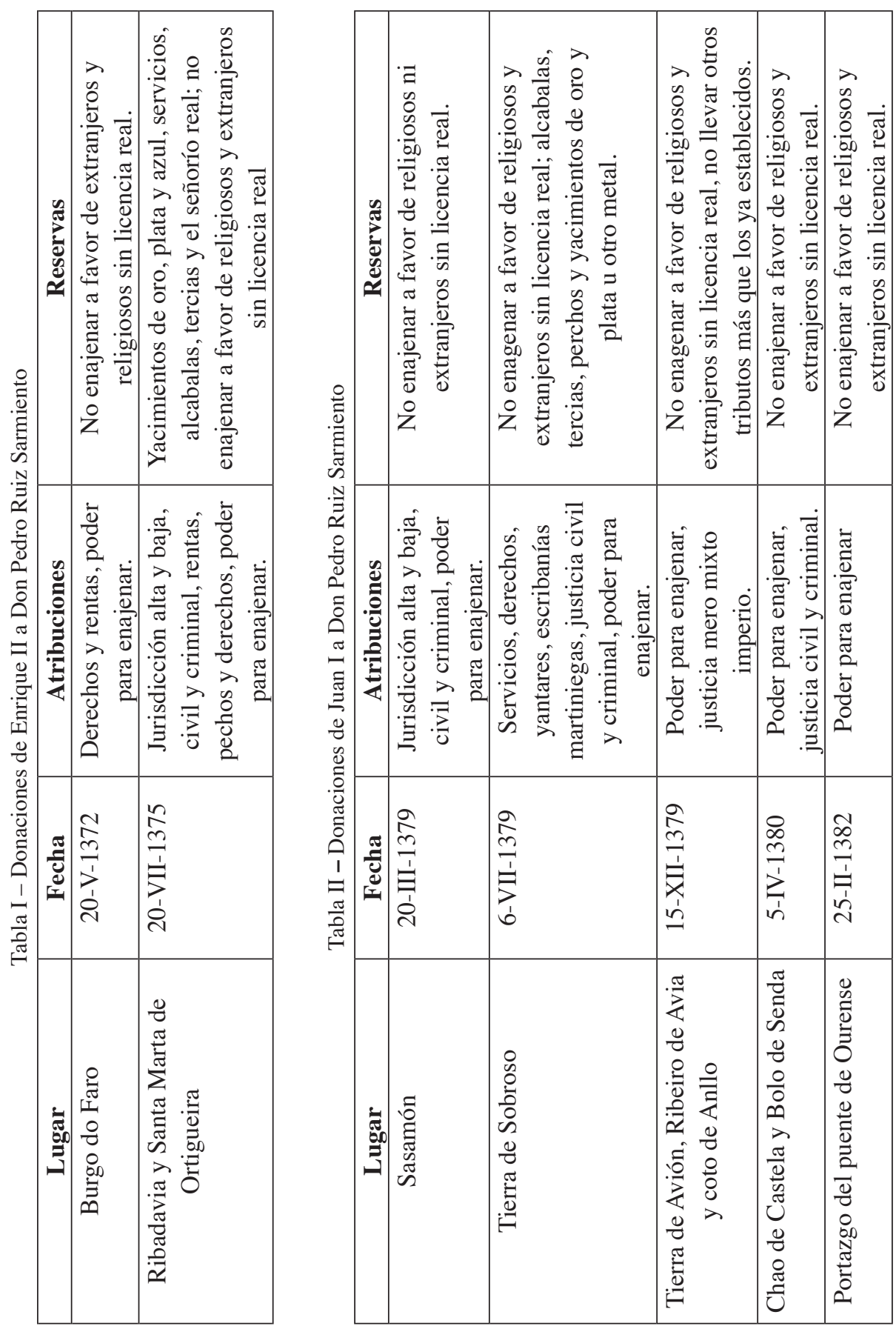


\section{APÉNDICE DOCUMENTAL}

\section{Sin fecha}

Traslado notarial de los diplomas de las concesiones otorgadas por Enrique II y Juan I a Don Pedro Ruiz Sarmiento, Adelantado Mayor de Galicia, a favor de su hijo Don Diego Pérez Sarmiento I, Adelantado Mayor de Galicia.

\section{A.H.U.S., Medinaceli, Ribadavia, M. 302 leg. 1 n. ${ }^{\circ} 1$}

En el nonbre de Dios, Padre e Fijo e Espiritu Santo que son tres personas e un Dios verdadero que bive e reyna por sienpre [xa]más e de la bien aventurada Virgen gloriosa Santa Maria, su madre, a quien nos tenemos por sennora e abogada en todos nuestros fechos e a onrra e serviçio de todos los santos de la corte çelestial.

Porque natural es en todas las cosas que Dios en este mundo fiso nasçer fenesçiese quando el tiene por bien e non suena cosa que fin non aya, salvo Dios que nunca ovo comienço nin avrá fin. E a semejança del ordeno las [...]s e la corte çelestial e como quier que quiso que oviese comienço, pero que non quiso que oviese fin, mas que [...]se sienpre e así como el es duradero, así quiso quel su reyno durase por sienpre. E porque todo [aquel] que en este mundo bien fase e bien sirve a su señor quiere aver galardón e que se non olvide nin se pier[da] e como quier que canse e mengue el curso de la vida deste mundo, aquéllo es lo que fimca (sic) en remen[brança] e él al mundo este bien es guiador de la su ánima ante Dios e por ende todos los onbres se deven me[...] de aquel reyno a que ha do yr a dar rasón de los reynos que les Dios en este mundo acomedó cuyo [...]d tiene. Por lo qual, entre todas las cosas son tenudos e les es dado a los reys de faser graçia e merçed, sennamente a do se demanda con rasón e con derecho, e el rey que la fase deve catar en ello tres cosas: la primera qué merçed es aquélla que le demanda, la segunda qué es el pro o el danno que ende le puede venir sy [la] fesiere, la terçera qué lugar es aquél a quien ha de faser la merçed e como gela meresçe. E por non aver en[...]do lo mandaron los reys poner en escripto en sus previllejos porque los otros que reynasen después dellos, oviesen el su lugar fuesen tenudos de guardar aquello e de lo levar adelante confirmado por sus previllejos.

Por ende, nos catando a esto queremos que sepan por este nuestro previllejo todos los ommes que agora son o seran aquí adelante, commo nos don Juan, por la graçia [de] Dyos, rey de Castiella, de Leon, de Toledo, de Gallisia, de Se[villa], de Córdova, de Murçia, de Jahén, del Algarbe, [de] Algesira e señor de Lara e de Viscaya e de Molina [...] uno con la reyna donna Leonor, 
mi [muger], vimos un alvalá del rey don Enrrique, nuestro padre [...], escripto en papel e firmado de su nonbre, fecho en esta guisa:

Nos el Rey.

Por faser bien e merçed [a vos don Pedro Ruys] Sarmiento, nuestro vasallo e nuestro Adelantado Mayor de Gallisia, por muchos serviçios e buenos [serviçios nos ave]des fecho e fasedes de cada día, dámosvos e fasemos merçed por juro de heredat para agora e [para si] enpre jamás para vos e para vuestros herederos e para los que de vos e dellos venieren de los lugares de Santa Marta de Or[ty]gera e de Ribadavia que a nos pertenesçen, con todos sus términos e con todos sus vasallos e vesinos de $\mathrm{m}[. .].[\mathrm{e}]$ montes e pastos e aguas corrientes e estantes e con la jurediçión alta e baxa e justiçia çevil e creminal [e con] el mero misto ynperio e con todas las rentas e pechos e derechos que a nos pertenesçen e pertenesçer deven en [qualquier] manera en los dichos lugares e en cada uno dellos e en sus términos commo dicho es. Pero retenemos [en] nos e para los reys que de nos venieren mineras de oro o de plata o de asul, sy las ha, e serviçios [...] [e] alcavalas e terçias e el sennorio real que nos y devemos aver. E desto sobredicho en la manera que sobre[dicha es,] vos damos para que lo podades dar, vender e enpennar e donar e trocar e enajenar e para que fagades en ello todo lo que quisiéredes, así commo de cosa vuestra propia. Pero que tenemos por bien que ninguna cosa destas [po]dades faser con omme de orden nin de religión nin de fuera de nuestro señorío sin nuestra liçençia e sin nuestro mandado. E por este nuestro alvalá o por el traslado signado de escrivano público mandamos a todos los vesinos e moradores [de] los dichos lugares e de sus términos e de cada uno dellos que vos resçiban e ayan por su sennor e vos recud[an e] fagan recudir con todas las rentas e pechos e derechos de los dichos lugares de Santa Marta de Ortygera e [d]e Ribadavia e de sus términos e de cada uno dellos e cunplan e obedescan vuestras cartas e vuestro mandado e vengan a vuestros enplasamientos e a vuestros llamamientos, así commo de su sennor. E los unos e los otros non fagan ende al por alguna manera, so pena de la [mi] merçed e de los cuerpos e de quanto han. E sobre esto // mandamos al nuestro chançiller e contadores e notarios e escrivanos e a los que están a la tabla de los nuestros sellos que den e sellen e lib[ren] a vos, el dicho Pedro Ruys Sarmiento, nuestros previllejos e cartas las que en esta rason ovierades mester. E non fagan ende a[1].

Fecho veinte dias de jullio, era de mill e quatroçientos e trese annos.

Nos el Rey.

E agora por quanto vos, el d[icho] Pedro Ruys Sarmiento, nuestro Adelantado Mayor en Gallisia, nos pedistes por merçed que vos confirmásemos el dicho 
alva[lá del] dicho Rey, nuestro padre que Dios perdone, e la merçed en él contenida e vos mandásemos dar nuestro previllejo en esta rasón, por conosçer a vos, el dicho Pedro Ruys Sarmiento, los grandes e altos serviçios que vos fesiestes al dicho Rey, nuestro padre que Dios perdone, e avedes fecho a nos e fasedes de cada día e por vos dar dello galardón e porque vos e [los] del vuestro linaje valades más e ayades con que más mejor nos podades servir e aviendo voluntad de vos heredar e[n] nuestros reynos, confirmámosvos la dicha merçed en el dicho alvalá contenida que el dicho Rey, nuestro padre que Dios perdone, [vos] fiso en la manera que dicha es e mandamos que vos vala e sea guardada en todo bien e conplidamente, segund en el dicho alvalá se contiene e segund que mejor e más conplidamente vos fue guardada en el tienpo del dicho [Rey], nuestro padre que Dios perdone, e en el nuestro fasta aquí, pero do non menguaredes la justiçia nos que la mandemos faser e [...]. E defendemos firmemente por este nuestro previllejio que ninguno nin alguno non sean osados de yr nin de pasar [nin de] enbargar nin de contrallar esta donaçión e merçed que vos nos fasemos nin de nos la menguar en todo nin en parte; e qualquier o qualesquier que lo fesieren, avrían nuestra yra e pecharnos yan en pena dies mill maravedís de la buena moneda e a vos, el dicho Pedro Ruys Sarmiento, o a los que de vos lo ovieren de heredar o a quien vuestra bos toviere, todos los [dannos] e menoscabos que por ende resçebiésedes doblados e demás a ellos o a lo que oviesen nos tornaremos por ella. [E] desto vos mandamos dar este nuestro previllejio rodado e sellado con nuestro sello de plomo colgado.

Fecho el p[revillejio] en las cortes que nos mandamos faser en la muy noble çibdat de Burgos, veynte e çinco dias de a[borroso], era de mill e quatroçientos e dies e siete annos.

E nos el sobredicho rey don Juan, reynante en uno con la [reyna] donna Leonor, mi muger, en Castiella, en León, en Toledo, en Gallisia, en Sevilla, en Córdova, en Murçia, en Jahén, en los Algarbes, en Algesira, en Lara, en Viscaya e en Molina, otorgamos este privillejio e non firmamos.

[...] Plaçençia, Notario Mayor de los privilejios rodados, lo m[andé] faser por mandado del Rey en el anno primero que el dicho rey don Juan reynó e se coronó e armó cavallero.

Yo Diego Ferrandes, escrivano del dicho sennor Rey, lo fise escripvir.

Ferrando Martines.

Vista.

Álvaro Martines, chançiller.

Alfonso Martines.

El infante don Donís, fijo del rey de Portogal, sennor de Alva, vasallo del Rey, confirmat. Don Alfonso, hermano del Rey, Conde de Noruenna e 
sennor de Cabrera e de Ribera, confirmat. Don Alfonso, fijo del infante Don Pedro, Marqués de Villena, Conde de Ribagorça e de Denia, vasallo del Rey, confirmat. Don Beltrán de Clauquén, Condeestable de Françia, va[sallo del] Rey, confirmat.

Don Pedro, arçobispo de Toledo, primado de las Espannas, confirmat. Don Pedro, arçobispo de Sevilla, confirmat. Don Juan, obispo de Çiguensa, Chan[çeller Ma]yor del Rey, confirmat. Don Diego, obispo de Burgos, confirmat. Don [...], obispo de Palençia, confirmat. Don Gonçalo, obispo de Calahorra, confirmat. Don [...] ]esma, confirmat. Don Hugo, obispo de Segovia, confirmat. Don Alonso, obispo de Ávila, confirmat. Don Niculás, obispo de Çiguença, confirmat. Don Pedro, obispo de Plasençia, [confirmat. Don] Pedro, obispo de Córdova, confirmat. Don Niculás, obispo de Cartajena, confirmat. Don Juan, obispo de Jahén, confirmat. Don Juan, obispo de Calis, confirmat.

Don Pedro [Ve]lasco, Camarero Mayor del Rey, confirmat. Don Pedro Manrrique, Adelantado Mayor de Castiella, confirmat. Don Juan Sanches Manuel, Conde de Carrión, Adelantado [Mayor] del Regno de Murçia, confirmat. Don Bernaldo de Bearve, Conde de Medina, vasallo del Rey, confirmat. Don Diego Gomes Manrrique confirmat. Don Juan Rodrigues de Cast[...], [confirmat]. Don Juan Rodrigues de Villalobos confirmat. Don Juan Ramires de Orellano, sennor de los Cameros, vasallo del Rey, confirmat. Don Beltrán de Guevara confirmat. [...] de Tovar, Guarda Mayor del Rey, confirmat. Don Arnao, sennor de Villalpando, vasallo del Rey, confirmat. Don Juan Martines de Luna, vasallo del R[ey], confirmat. [Don] Nunno Nunnes Daça confirmat. Don Nunno Alvares Daça confirmat. Don Fadrique, hermano del Rey, Duque de Benavente, confirmat. Don Pedro, primo del [Rey, Conde] de Trastámara e de Lemos e de Sarria, confirmat.

Don Rodrigo, arçobispo de Santiago, Capellán Mayor del Rey e Notario Mayor del Reyno de León, confirmat. [...], obispo de León, confirmat. Don Gutierre, obispo de Oviedo, confirmat. Don Alfonso, obispo de Astorga, confirmat. Don Martín, obispo de Çamora, confirmat. Don Alfonso, obispo de Salamanca, [confirmat. Don] Juan, obispo de Çibdat, confirmat. Don frey Guillelme, obispo de Coria, confirmat. Don Ferrando, obispo de Badajós, confirmat. Don Françisco, obispo de Mondonnedo, confirmat. Don [...] de Tuy, confirmat. Don Gonçalo, obispo de Orense, confirmat. Don Pedro, obispo de Lugo, confirmat.

Don Ferrando Osorres, Maestre de la Cavallería de la Orden de Santiago, confirmat. Don D[...] de Calatrava, confirmat. Don Pedro Ruys Sarmiento, Adelantado Mayor de Gallisia, confirmat. Don Juan Alonso de Gusmán confirmat. Don Gonçalo Nunnes de Gusmán confirmat. Don Pedro [...], Conde 
de Ribadeo, vasallo del Rey, confirmat. Don Alonso Telles Girón confirmat. Don Pedro Alonso Girón confirmat. Don Alonso Ferrandes de Montemayor, Adelantado Mayor [...], confirmat. Don Gonçalo Ferrandes, sennor de Aguilar, confirmat. Don Pedro Nunnes, maestre de la cavallería de la Orden de Calatrava, confirmat. El prior de Sant Juan confirmat. Don [...] Quinnones, Adelantado Mayor de León, confirmat. Juan Nunnes de Villasana, Justiçia Mayor de la Casa del Rey, confirmat. Don Ferrando Sanches de Tovar, Almirante [Mayor de la] Mar, confirmat. Diego Lopes Pacheco, Notario Mayor de Castilla, confirmat. Pedro Sanches de Toledo, alcalde mayor de Toledo e Notario Mayor del Reyno de [...], [confirmat]. Pedro Suares de Gusmán, Notario Mayor del Andoliçía, confirmat.

\section{// Nos el Rey.}

Por faser bien e merçed a vos Pedro Ruys Sarmiento, nuestro vasallo e nuestro Adelantado Mayor de Gallisia, por muchos serviçios e buenos que fesiestes al rey Don Enrrique, nuestro padre que Dios perdone, e a nos fasedes de aquí adelante, dámosvos por juro de heredat para sienpre jamás para vos e para vuestros herederos e para los que de vos venieren de linia derecha e de logitymo (sic) matrimonio las tierras de Avión e de Ribero de Avia e del coto de Anno, con todos sus términos e pertenençias e montes e prados e pastos e aguas corrientes e estantes e con todos los vasallos e vesinos e moradores de las dichas tierras e en cada una dellas. E esto que dicho es, vos damos para que lo podades dar e vender e enpennar e trocar e enajenar e donar e cambiar e para que fagades dellas e en ellas todo lo que quisiéredes, así como de vuestra cosa propia, pero que tenemos por bien que ninguna destas cosas non podades faser con ome de orden nin de religión nin de fuera de nuestro sennorio sin nuestra liçençia e sin nuestro mandado. Pero todavía tenemos por bien e es la nuestra merçed que vos non podades echar nin levar nin echedes nin llevedes en las dichas tierras nin en alguna dellas otros pechos nin pedidos nin otras cosas algunas, salvo aquellas que echastes e llevastes en tienpo del Rey, nuestro padre, e que usedes con ellos así en esto como en fecho de la justiçia e del mero misto inperio e con todas las otras cosas, segund que usastes en tienpo del dicho Rey, nuestro padre, e non de otra guisa ninguna, ca así es nuestra merçed. E sobre esto mandamos al nuestro chançiller e notarios e escrivanos e a los que están a la tabla de los nuestros sellos que vos den nuestro privillejo e cartas las que en esta rasón oviéredes mester, segund la forma e ordenanças que el dicho Rey, nuestro padre, e nos ordenamos. E desto vos mandamos dar este nuestro alvalá en que escrivimos nuestro nonbre. 
Fecho quinse dias de desienbre, era de mill e quatroçientos e dies e siete años.

Nos el Rey.

Yo Diego Ferrandes, escrivano del dicho señor Rey, la fis escrivir por su mandado.

En el nonbre de Dios, Padre e Fijo e Espíritu Santo que son tres personas e un solo Dios verdadero que bive e reyna por sienpre jamás e de la bienaventurada gloriosa Santa Maria, su madre, [a qui]en nos tenemos por sennora e abogada en todos nuestros [...] e onrra e serviçio de todos los santos de la corte çelestial.

Porque natural cosa es que todas las cosas que Dios en este [mundo] fiso nasçer, fesiere quando él quiere por bie[n] [...] cosa que fin non aya, salvo Dios que nunca ovo comienço nin fin e a semejança del ordenó los ángeles e la [corte] çelestial. E commo quier que quiso que oviese comienço, pero que [...] oviese fin nin que durase sienpre e así [...] el que duradero, así quiso del su reyno durase por sienpre o todo onbre que en este mundo bien fase e bien sirve [...] sennor quiere aver gallardón que se non olvide nin se pierda [com] mo quier que canse e mengue el curso de la vida des[te] mundo, aquello es lo que finca en remenbrança por él al mundo bien es guarda de la su alma ante Dios. E por ende [todos] los onbres se deven menbrar de aquel reyno a que ha de yr a faser de los reynos que les Dios en este mundo acomendó cuyo lugar tyene. Por lo qual, entre todas las cosas son te[nu]dos e les es dado a los reyes de faser graçia e merçed, sennaladamente a do se demanda con rasón e con derecho e el rey que la fase [de]ve catar en ellos tres cosas: la primera, qué merçed es aquélla que le demandan; la segunda, qué es el pro o el danno que ende le puede venir sy la fisiere; la terçera, qué lugar es aquél a quien ha de faser la merçed e como gela meresçe. E por non caer en olvido lo [man]daran los reyes poner en escripto en sus previllejos porque los otros que reynasen después dellos e toviesen el su lugar, fuesen [te]nudos de guardar en ello e de lo levar adelante conservando por sus previlleios.

E por ende, nos acatando a esto, queremos que se[pan] por este nuestro previllejo todos los los omes que agora son o serán de aquí adelante, como nos Don Juan, por la graçia de Dios, rey de [Cas]tiella, de León, de Toledo, de Gallisia, de Sevilla, de Córdova, de Muçia, de Jahén, del Algarbe, de Algesira, sennor de Lara e de [Vis]caya e de Molina, reynante en uno con la reyna donna Leonor, mi muger. Vimos una carta del rey Don Enrrique, nuestro padre [que] Dios perdone, escripta en papel e firmada de su nonbre fecha en esta guisa: 
Don Enrrique, por la graçia de Dios, rey de Castiella, [de] León, de Toledo, de Gallisia, de Sevilla, de Córdova, de Muçia, de Jahén, del Algarbe, de Algesira e sennor de Molina.

Por faser bien e merçed a vos Pedro Ruys Sarmiento, nuestro Adelantado Mayor en Gallisia, por muchos serviçios e buenos que fesiestes e nos fasedes cada día, dámosvos el Burgo del Faro con todos sus derechos y pertenençias, quantas ha e deve aver e le pertenesçen, e todos los cotos e tierras que andodieron en renta con el dicho lugar fasta aquí. E dámosvos el dicho lugar con todo lo que [dich]o es por juro de heredat para vos e para los que lo vuestro ovieren de aver e de heredar para que lo podades vender e enpennar e dar e trocar e enajenar e faser dello todo lo que vos quisieredes e vuestra voluntad fuere, asi commo de vuestra cosa [pro]pia, pero que lo non podades faser con onbre de orden nin de religión nin de fuera de nuestros reynos sin nuestro mandado. E por esta nuestra carta mandamos a todos los vesinos e moradores en el dicho lugar del Burgo e en los cotos e tierras que andodieron en renta con el [dich]o lugar fasta aquí como dicho es, que vos resçiban e ayan por sennor e recudan e fagan recodyr a vos el dicho Pedro Ruys [o] al que lo oviere de aver por vos con todos los frutos e rentas e pechos e derechos e con todas las otras cosas que le pertenesçen, // s[egund] que mejor e más conplidamente lo dávades e pagávades e recudíades con ello a don Fernando de Castro en el tienpo que era [...].

[E non fag]ades ende al por alguna manera, so pena de la nuestra merçed e de los cuerpos e de lo que avedes.

Dada en Portomaryn, sellada con [el sello de la] poridat, veinte dias de mayo, era de mill quatroçentos e dies annos.

Nos el Rey.

E agora, por quanto vos, el dicho [Pedro Ruys Sarmiento], nuestro Adelantado Mayor en Gallisia, nos pedistes por merçed que vos confirmásemos la dicha carta del dicho Rey, nuestro padre que [Dios perdone, e] la merçed en ella contenida e vos mandásemos dar nuestro privillejio en esta rasón. E por conosçer a vos, el dicho Pedro Ruys Sarmiento, [los muy] altos serviçios que vos fesiestes al dicho Rey, nuestro padre que Dios perdone, e avedes fecho a nos e fasedes de cada día e [...] dello galardón e porque vos e los del vuestro linaje valades más e ayades con que nos mejor podades servir e [aviendo vol]untad de vos heredar en los nuestros reynos, confirmámosvos la dicha merçed en la dicha carta contenida que el dicho Rey, [nuestro padre] que Dios perdone, fiso en la manera que dicha es e mandamos que vos vala e sea guardada en todo e bien y conplida[mente lo que] en la dicha carta se contiene e segund que mejor e más conplidamente vos fue guardada en el tienpo del dicho Rey, nuestro [padre que 
Dios perdone], e en el nuestro fasta aquí. E defendemos firmemente por este nuestro privillejio que ninguno nin algunos non sean osados de [ir nin de p]asar nin de enbargar nin de contrallar esta donaçión e merçed que vos nos fasemos, confirmando dicha donaçión e merçed el dicho Rey, nuestro padre que Dios perdone, vos fiso e demás la non menguar en todo nin en parte. E qualquier o qualesquier que lo [fesieren, abrán la nuest]ra yra e pecharnos yan en pena dies mill maravedís de la buena moneda e a vos, el dicho Pedro Ruys Sarmiento, o a los que [de vos lo] ovieren de heredar o a quien vuestra bos toviere, todos los dannos e menoscabos que por ende resçebiesedes dobla[dos] [...] as a ellos y a lo que oviesen nos tornaremos por ello. E desto vos mandamos dar este nuestro privillejio rodado e s[ellado con] nuestro sello de plomo colgado.

Fecho el privillejio con las cosas que nos mandamos faser en la muy noble çibdat de Bur[gos] [...] e siete días de agosto, era de mill quatroçientos e dies e siete annos.

E nos, el sobredicho rey Don Juan, rey[nante en uno] con la reyna donna Leonor, mi muger, en Castiella e en León e en Gallisia e en Sevilla e en Córdova e en Murçia, [en Jahén], en el Algarbe, en Algesira, en Lara, en Viscaya, en Molina, otorgamos este privillejo e confirmámoslo.

Don Pedro, ob[ispo] [...], Notario Mayor de los privillejos rodados, lo mandó faser por mandado del Rey en el anno primero que el sobredicho [Rey] reynó e coronó e armó cavallero.

Yo Diego Ferrandes, escrivano del dicho sennor Rey, lo fis escribir.

Juan Suares [...]. Alvar Martines, chançiller. Alfonso Martines. El infante don Donis, [...] rey de Portogal, sennor de Alvar de Tormes, vasallo del Rey [...]ermano del Rey, Conde de Norenna e sennor de Cabrera e de Ribe[ra] confirmat. Don Alfonso, fijo del infante Don Pedro de Aragón, Marqués de Vill[...], Ribagorça e de De[...], vasallo del Rey, confirmat. Don Beltrán de Clauquen, [Con]deestable de Françia, vasallo del Rey, confirmat.

Don Pedro, arçob[ispo] [...] [Pri]mado de las Espannas, confirmat. Don Pedro, arçobispo de Sevilla, [confirmat]. Don Juan, obispo de Çiguença, Chançeller Mayor del [Rey, confirmat]. [...], obispo de Burgos, confirmat. Don [...], obispo de Palençia, confirmat. Don [...], obispo de Calahorra, confirmat. Don [...], obispo de Osma, confirmat. [...] Segovia, confirmat. Don Alonso, obispo de Ávila, confirmat. Don Niculás, obispo de Çiguensa, confirmat. Don Pedro, obispo de Plasençia, confirmat. Don [...] [obispo de] Córdova, confirmat. Don Niculás, obispo de [...], confirmat. Don Juan, obispo de Jahén, confirmat. Don Juan, obispo de Calis (sic), confirmat.

Don Pedro Ferrandes, [...] Mayor del Rey, confirmat. Don Pedro Manrrique, Adelantado Mayor de Castiella, confirmat. Don Juan Sanches Manuel, Conde 
de Carrión, Adelantado [Mayor] del Reyno de Murçia, confirmat. Don Bernalde de Beague, Conde de Medina, vasallo del Rey, confirmat. Don Diego Gomes [...] [confirmat]. [Don] Juan Rodrigues de Castanneda confirmat. Don Juan Rodrigues de Villalobos confirmat. Don Juan Ramires de Orellano, sennor de los Cameros, vas[allo del Rey], confirmat. Don Beltrán de Guevara confirmat. Sancho Ferrandes de Tovar, Guarda Mayor del Rey, confirmat. Don Arnao, sennor de Villalpando, va[sallo del Rey], confirmat. Don Juan Martines de Luna, vasallo del Rey, confirmat. Don Nunno Nunnes Daça confirmat. Don Nunno Alvares Daça confirmat. Don Fadri[que] [...] Rey, Duque de Benavente, confirmat. Don Pedro, primo del Rey, Conde de Trastámara e de Lemos e de Sarria, confirmat.

Don Rodrigo, arçobispo de S[...] Mayor del Rey e Notario Mayor del Reyno de León, confirmat. Don Fernando, obispo de León, confirmat. Don Gutierre, obispo de Oviedo, confirmat. Don Alonso, obispo [de] [...], confirmat. Don Nunno, obispo de Çamora, confirmat. Don Alonso, obispo de Salamanca, confirmat. Don Juan, obispo de Çibdat (sic), confirmat. Don frey Guillelme, obispo de [...] [confirmat]. Don Ferrando, obispo de Badajós, confirmat. Don Françisco, obispo de Mondonnedo, confirmat. Don Juan, obispo de Tuy, confirmat. Don Gonçalo, obispo de O[...], confirmat. [...] obispo de Lugo, confirmat.

Don Ferrando Osores, Maestre de la Cavallería de la Orden de Santiago, confirmat. Don Diego Martines, Maestre de Cal[...], confirmat. Pedro Ruys Sarmiento, Adelantado Mayor de Gallisia, confirmat. Don Juan Alonso de Gusmán, Conde de Niebla, confirmat. Don Rodrigo Pe[res] [...], confirmat. Don Alvar Peres de Gusmán, Aguasil Mayor de Sevilla, confirmat. Don Manuel Nunnes de Gusmán confirmat. Don Gonçalo Nunnes de Gus[mán confirmat]. [Don Rodrig]o de Vilenes, Conde de Ribadeo, vasallo del Rey, confirmat. Don Alonso Telles Girón confirmat. Don Pedro Alonso Girón confirmat. Don Alonso Ferrandes de [...], Adelantado Mayor de la Frontera, confirmat. Don Gonçalo Ferrandes, sennor de Aguilar, confirmat. Don Pedro Martines, Maestre de la Cavallería [de la Orden] de Calatrava, confirmat. El prior de Sant Juan confirmat. Don Pedro Suares de Quinnones, Adelantado Mayor de León, confirmat. Juan Nunnes de [...], Justiçia Mayor de la Casa del Rey, confirmat. Don Ferrando Sanches de Tovar, Almirante Mayor de la Mar, confirmat. Diego Lopes Pal[...] Mayor de Castiella, confirmat. Pedro Suares de Toledo, alcalde mayor de Toledo e Notario Mayor del Reyno de Toledo, confirmat. Pedro [...], Notario Mayor del Andaloçía, confirmat.

// En el nonbre de Dios, Padre e Fijo e Espíritu Santo que son tres personas e un Dios verdadero que bive e regna por sienpre [ja]más e de la bien aventurada 
Virgen gloriosa Santa María, su madre, a quien nos tenemos por sennora e por aboga[da] en todos nuestros fechos e a onrra e a serviçio de todos los santos de la corte çelestial.

Porque natural cosa es que todas [las] cosas que Dios en este mundo fiso nasçer, quiso fenesçiesen quando él tiene por bien e non finar otra cosa que non aya, salvo Dios que nunca ovo comienço nin avra fin, e a semejança del ordenó los ángeles e la corte çeles[ti]al e como quier quiso que oviese comienço non quiso que oviese fin, mas que durase sienpre e así commo él es duradero, asy quiso que el reyno suio que durase por sienpre. E porque todo ome que en este mundo bien fas e bien sirve a su sennor [...] aver galardón que se non olvide nin se pierda, ca como quier que canse e mengue el cuerpo de la vida deste mundo, aquello lo que finca en remenbrança por él al mundo e este bien es gyador de la su alma ante Dios e por ende todos los [...] se deven menbrar de aquel reyno a que han de yr a dar rasón de los reynos que les Dios en este mundo encomendo e [...]io lugar tiene. Por lo qual, entre todas las cosas son tenudos e les es dado a los reyes de faser graçia e merçed, sennaladamente do se demanda con derecho e con rasón, ca el rey ha de catar en ello tres cosas: la primera, qué merçed es aquélla que le demandan; la segunda, qué es el pro o el danno que dende le puede venir sy la fisiere; la terçera, qué lugar es aquél en quien ha de faser la merçed e commo gela meresçe. E por non caer en olvido, lo mandaron los reyes poner en escripto en sus [priv]illejos porque los otros que reynasen después dellos e toviesen el su lugar fuesen tenudos de guardar aquello e de lo [...] adelante confirmándolo por sus previllejos.

E por ende, nos acatando esto queremos que sepan por este nuestro previllejo todos [los o]mes que agora son o serán de aquí adelante, commo nos don Juan, por la graçia de Dios, rey de Castiella, de León, de Toledo, [de Ga]llisia, de Sevilla, de Córdova, de Muçia, de Jahén, del Algarbe, de Algesira e sennor de Lara e de Viscaya e de Molina, [reynan]te en uno con la reyna donna Leonor, mi muger, en Castiella e en León. Vimos un nuestro alvalá escripto en [...] e firmado de nuestro nonbre fecho en esta guisa:

Yo el Rey.

Por faser bien e merçed a vos Pedro Ruys Sarmiento, mi vasallo [e] mi Adelantado Mayor de Gallisia, por muchos serviçios e buenos que fesiestes al rey don Enrrique, mi padre que Dios [perdo]ne, y a mí faredes de aquí adelante, dovos por juro de heredat para sienpre jamás para vos e para vuestros herederos [e para] los que de vos venieren de linna derecha e de leg[ítim]o matrimonio la tierra de Sobroso que es en la merindat de [...] en el reyno de Gallisia, con todos sus términos e pertenençias e montes e prados e pastos e aguas 
corrientes [e estantes e] con todos sus vasallos e vesinos e moradores e serviçios e pechos e derechos e escrivanías e yantares e martyniegas [e con] la justiçia çevil e creminal, mero e misto inperio [e] con todas las otras cosas que a mí pertenesçen e pertenesçer deven [en] qualquier manera en la dicha tierra de Sobroso. E todo esto sobredicho en la manera que dicha es, vos do para que lo podades [dar] e vender e enpennar e trocar e enajenar e donar e para que fagades dello e en ello todo lo que quisiéredes, asi como [de] cosa vuestra propia, pero que tengo por bien que esto que lo non podades faser con onbre de orden nin de religión nin de fuera del [...] sennorío sin mi liçençia e sin mi mandamiento. E por este mi alvalá o por el traslado del signado de escrivano público mando al conçejo e vesinos e moradores de la dicha tierra de Sobroso e a cada uno dellos que agora son o serán de aquí adelante e a qualesquier dellos, que vos ayan e resçiban por su sennor e obedescan e cunplan vuestras cartas e vuestros mandamientos [...] osen con los alcaldes e alguasil e escrivanos e otros ofiçiales que vos posiéredes en la dicha tierra e vos recudan e fagan recudir [con] todas las rentas e pechos e derechos de la dicha tierra, bien e conplidamente. E non fagan ende al, so pena de la mi merçed e de los cuerpos e de quanto han. E sobre esto mando al mi chançeller e notarios e escrivanos e a los que están [a] la tabla de los mis sellos que vos den previllejo e cartas mías, las que mester oviéredes en esta rasón, las más con[p]lidas que ser podieren.

Fecho seys dias de jullio, era de mill e quatroçientos e dies e syete annos. Yo el Rey.

E por [qua]nto vos, el dicho Pedro Ruys Sarmiento, nos pediestes por merçed que vos confirmásemos la dicha merçed que vos fesiéramos e vos [man]dásemos dar nuestro previllejo en esta rasón. E por conosçer a vos, el dicho Pedro Ruys, los grandes e altos serviçios que vos fesiestes al dicho Rey, nuestro padre que Dios perdone, e avedes fecho a nos e fasedes de cada día e por vos dar dello [ga] lardón aviendo voluntad de vos heredar en los nuestros regnos, confirmámosvos la dicha merçed que vos fesiemos con la [...] que dicha es e mandamos que vos vala e vos sea guardada bien e conplidamente, segund dicho es e en el dicho [nuest]ro alvalá se contiene. Pero tenemos por bien do vos menguaredes la justiçia que nos gela mandemos faser e conplir [e] retenemos para nos e para los reyes que después de nos reynaren en Castiella e en León alcavalas e monedas e terçias e los [...]s, pechos quando los echáremos en los nuestros reynos para los nuestros menesteres e mineras de oro e de plata e de asul // e de otro metal si los y oviere. E por este nuestro previllejo vos mandamos e damos poder que podades poner e pongades en [la] tierra de Sobroso alcaldes e jueses e merinos e escrivanos públicos e los otros ofiçiales que entendiéredes que cunplen. 
E defendem[os fir]memente por este nuestro previllejo que ninguno nin algunos non sean osados de vos yr nin pasar nin enbargar nin contrallar esta do[naçión] e merçed e confirmaçión que vos nos fasemos nin de vos la menguar en todo nin en parte, sinón qualquier o qualesquier que lo contra[rio hiziere] avrían nuestra yra e pecharnos yan en pena dies mill maravedís de la buena moneda e a vos, el dicho Pedro Ruys Sarmiento, o a los que lo ovieren de heredar o a quien vuestra bos toviese, todos los dannos e los menoscabos que por ende resçebiésedes doblados demás a ellos e a lo que oviesen nos tornaríamos por ello. E desto vos mandamos dar este nuestro previllejo rodado e sella[do con] nuestro sello de plomo.

Fecho el previllejo en las Cortes que nos mandamos faser en la muy noble çibdat de Burgos, dies e n[ueve] dias de agosto, era de mill e quatroçientos e dies e siete annos.

E nos, el sobredicho rey don Juan, reynante en uno con la [reyna] donna Leonor, mi muger, en Castiella e en León, en Toledo, en Gallisia, en Sevilla, en Córdova, en Murçia, en Jahén, en Alg[arbes], en Algesira, en Lara, en Viscaya, en Molina, otorgamos este privillejo e confirmámoslo.

Don Pedro, obispo de Plasençia, [Notario] Mayor de los previllejos rodados, lo mandó faser por mandado del Rey en el anno primero que sobredicho rey don Juan reynó e coronó e armó cavallero.

Yo Diego Ferrandes, escrivano del dicho señor Rey, lo fis escrivir.

Juan Ferrandes. Martín Yannes.

Vista.

Alvar [...], chançiller. Alfonso Martines.

Nos el Rey.

Por faser bien e merçed a vos, Pedro Ruys Sarmiento, nuestro vasallo e nuestro Adelantado Mayor de Gallisia, por muchos serviçios [e] buenos que fesiestes al rey don Enrrique, nuestro padre que Dios perdone, e a nos fasedes de aquí adelante, dámosvos por juro d[e here]dat para vos e para vuestros herederos para sienpre jamás e para los que de vos venieren de linna derecha e de legíty[mo ma]trimonio las tierras e cotos del Chano de Castela e del Bolo de Senda, con todos sus términos e pertenençias e con to[dos sus] vasallos e vesinos e moradores en las dichas tierras e en cada una dellas. E esto que dicho es vos damos para que lo $\mathrm{p}$ [odades] dar e vender e enpennar e trocar e enagenar e donar e cambiar para que fagades dellas e en ellas todo lo que quisié[rades] así commo de vuestra cosa propia. Pero que tenemos por bien [que] estas cosas non podades faser con ome de orden nin [de re]ligión nin de fuera de nuestro sennorío sin nuestro mandado e [...] con ellas, así en esto como en fecho de la 
justiçia [...] misto inperio e con todas las otras cosas, segund que vos [usastes en] tienpo del Rey, nuestro padre, e non de otra guisa ninguna [...]. E sobre esto mandamos al nuestro chançeller e notarios [...] e a los que están a la tabla de los nuestros sellos que [...] previllejo e cartas las que en esta rasón oviéredes mester [...] forma e ordenanças que el dicho Rey, nuestro padre, [...]ramos. E desto vos mandamos dar este nuestro alvalá en que escrivimos nuestro nonbre.

Fecho çinco dias de abril, era de mill [e quatro]çientos e dies e ocho annos.

Yo, Diego Ferrandes, escrivano del dicho sennor Rey, la fis escrivir por su mandado.

Nos el R[ey.]

En el nonbre de Dios, Padre e Fijo e Espirítu Santo que son tres personas e un solo Dios verdadero sin otro departermiento alguno e de la b[iena]venturada sennora salva Santa María, su madre, a quien nos tenemos por sennora e por abogada e medianera entre él e nos por bien nuestro, es tan gran cosa e tan buena e non alcança ome por ello tan solamente este mundo, mas aun alcança el otro ha[...]gança para sienpre. E porque entre todas las cosas que a los reyes son dadas, espeçialmente les es dado de faser bien e merçed [...] allí do gelo demandan con rasón e el rey que lo fase debe curar en ello tres cosas: la primera, qué cosa es aquélla que le demandan; la [se]gunda, quién es aquél que gela pide e si la meresçe e la terçera, qué es el pro e el danno que se le ende puede segyr.

E por ende [...] a todo esto, queremos que sepan por este nuestro privillejo quantos agora son o serán de aquí adelante, como nos, don Juan, por la graçia de [Dios], rey de Castiella, de Toledo, de León, de Gallisia, de Sevilla, de Córdova, de Murçia, de Jahén, del Algarbe, de Algesira e sennor de Viscaya e de Molina.

Conosçiendo a vos, Pedro Ruys Sarmiento, nuestro Adelantado Mayor en el Reyno de Gallisia, quanta lea[ltad] en vos falló sienpre el rey don Enrrique, nuestro padre que Dios perdone, e otrosí nos después que acá reynamos e los muy [alto]s e sennalados serviçios que vos fesiestes al dicho Rey, nuestro padre, e a nos fasedes de cada día e por vos faser bien e merçed [e] dar galardón dello, dámosvos que ayades e tengades de nos en merçed el portadgo de la puente de Orense e que lo ayades e tengades de aquí adelante por juro de heredat para agora e para sienpre jamás, para vos e para vuestros herederos e para los [que] de vos venieren, para dar e vender e enpennar e trocar e cambiar e faser del e en él todo lo que quisierédes e por bien tovié[redes // commo de] cosa vuestra 
propia. Pero que tenemos por bien que lo non podades faser con omme de orden nin de religión nin de fuera del nuestro sennorío [sin nuest]ra liçençia e mandado. E sobre esto, mandamos al conçejo e ommes buenos de la çibdat de Orense e a los cavalleros e escuderos dever fasienda del dicho conçejo, que vos recudan e fagan recudir con todas las rentas e derechos que el dicho portadgo ren[tase] e a él pertenesçiere en qualquier manera este anno de la era deste nuestro privillejo e dende en adelante en cada anno para sienpre [jamás], para vos e para vuestros herederos e para los que de vos venieren para sienpre jamás commo dicho es. E que vos recudan e fagan [recu]dir con todas las rentas e derechos que sobredichas son este dicho anno a vos e a los que después de vos venieren para sienpre jamás [e] a los plasos e en la manera que fasta aquí a nos lo acostunbraron a pagar. Que vos non demanden otros privillejos nin carta mensajera sobre esta rasón, ca es vuestra carta de pago o con la de vuestros herederos que después de vos venieren agora e sienpre. [E por el] traslado deste nuestro privillejo signado de escribano público, mandamos a qualquier thesorero o recabdador que agora [es] o fuere de aquí adelante en el dicho Reyno de Gallisia, que resçiba en cuenta al dicho conçejo de la dicha çibdat de Orense [tod]o lo que así rendiere el dicho portadgo agora e sienpre, pues que nos fasemos merçed del por juro de heredat para sienpre jamás commo dicho es. E los unos e os otros non fagan ende al, so pena de la nuestra merçed e de dies mill maravedíes desta moneda usual [a ca]da uno dellos para la nuestra cámara. E si lo así faser e conplir non quisieren, por este nuestro previllejo e por el traslado del signado, [commo] dicho es, mandamos a todos los conçejos, alcaldes, merinos, alguasiles, jurados, jueses, justiçias e otros ofiçiales qualesquier [de] todas las çibdades e villas e lugares de los nuestros reynos, que prendan e tomen tantos bienes del dicho conçejo de la dicha çib[dat] de Orense, asy muebles commo rayses do quier que los fallaren, e los vendan luego así commo por maravedíes del nuestro aver. E [lo] que valieren, que entreguen e fagan pago a vos, el dicho Pedro Ruys Sarmiento, nuestro Adelantado Mayor, e a los que después de vos [venieren] para sienpre jamás, con todas sus rentas e derechos que el dicho portadgo rendiere e a él pertenesçiere en qualquier manera para sí [e] en la manera que dicha es. E que vos guarden e anparen con esta dicha merçed que vos nos fasemos agora e sienpre jamás. E non vayan nin pasen contra ella nin contra parte della [en] algún tienpo por alguna manera, ca qualquier que lo fesiere, avería mi yra e demás pecharnos yan en pena los dichos dies mill maravedíes para la nuestra cámara e a vos o a quien vuestra bos toviese [o los] dichos vuestros herederos los que después de vos venieren, [todos] los dannos e menoscabos que por ende resçebiésedes doblados. [E] demás por qualquier o qualesquier dellos [...] de lo así faser e conplir, mandamos al omme que vos este nuestro mostrare o el 
traslado del signado de escrivano publico commo dicho es, que vos enplase que parescades ante nos donde quiera que nos seamos con la dicha pena del día que vos enplazare a quinse dias primeros seg[uientes] so la dicha pena a desir por qual razón non conplides nuestro mandado. [E desto] nos mandamos dar este nuestro privillejo escripto en pergamino de cuero sellado con nuestro sello de plomo pendiente.

Dado en Segovia, a veinte e çinco días de febrero, era de mill e quatroçientos e veynte annos.

Yo Fernando Gomes la fis escribir por mandado [del Rey].

Alvarus de Cretorun, dotor. Ferrando Gomes. Martín Ferrandes. Gonçalo Ferrandes. Alfonso Sanches. Juan Gomes. Álvaro.

Los dichos previllejos e alvalás e escipturas de los sobredichos reys suso contenidas mostradas por el dicho adelantado [don D]iego Peres Sarmiento e leydas por mí, el dicho escrivano e notario, ante el dicho alcalde e ante los testigos que adelante [...]go, el dicho Adelantado dixo que por rasón que él tenía de enbiar los dichos previllejos e alvalás e otras cartas por el Reyno de Castiella e por el Reyno de Gallisia a algunas partes a do se entendía aprovechar dellas, resçelava que se podían perder e marrotar (sic) por robo o por furto o por fuego o por agua o por otra ocasión por lo qual le podría ende recresçer danno e pérdida. Dixo que pedía e pedió al dicho Juan Martines [...] al[...] dicho que diese liçençia e poder e aturidat a mí, el dicho escrivano e notario, para que sacase o fesiese sacar de los previllejos e alvalás e otras escripturas un traslado o dos o tres o más, quantos le conpliesen e mester lo fuesen, [e] signase con mi signo e que el dicho alcalde que posiese su decreto en el traslado o traslados que yo, el dicho escrivano, sacase o fesiese sacar e así signase de mi signo para que valiesen e fesiesen fe ende quier que paresciesen commo oreginales mesmos de los dichos previllejos e alvalás e escripturas, así commo escripturas públicas pueden e de[ven v]aler de derecho. E luego, el dicho Juan Martines Charahón, alcallde sobredicho, dixo que veya e oya lo que el dicho a[delantado don] Diego Peres Sarmiento desía e pedía e que veya los dichos previllejos e alvalás e escripturas que ante él mostrava e [...] e las veya sanas e non rotas nin chançelladas nin en algún lugar dellas sospechoso nin dubdoso, e por [...] que dava e dio liçençia e poder e abtoridat a mí, el dicho escrivano e notario, para que sacase o fisiese sacar de los dichos previllejos e alvalás e escripturas un traslado o dos o tres o más, los que mester oviese e conpliese al Adelantado, e lo signase con mi signo e que ponía e puso en el tal traslado o traslados que así paresçiesen // signados de mi signo su decreto e mandamiento que valiese e fesiese fe en todo tienpo y en todo lugar, do q[uier] que paresçiesen, 
así commo las oreginales mesmas e así commo escripturas públicas pueden e deven valer de derecho.

Desto son testigos que estavan presentes e vieron e oyeron leer los dichos previllejos e alvalás e escripturas e las vieron conçertar con este dicho traslado en la dicha villa de Palençuela: Sancho de Velasco e Gonçalo Sanches de Tonnino e Rodrigo de Sandoval e Pedro Sanches de Burgos, escuderos del dicho Adelantado, e Llorenço Martines e Diego Lanares e Diego Martines, alcallde, vesinos de Palençuela, e otros.

E yo, Juan Fernandes de Valladolid, escrivano e notario público sobredicho, fuy presente con los dichos testigos e vi e ley todos los dichos previllejos e alvalás e escreturas de las quales escriví e saqué este traslado que suso va escripto en estas seys fojas e más esta foja en que va mío signo desto quaderno de papel, e fue presente ante el dicho alcalde a todo lo que dicho es e [...] dimiento del dicho adelantado Diego Peres Sarmiento e con liçençia e poder e mandamiento e abto[ridad] del dicho alcallde Juan Martines, escriví e saqué este traslado de los dichos previllejos e alvalás e escripturas e conçer[...] con ellos ante el dicho alcalde e ante los dichos testigos, en el qual dicho traslado el dicho Juan Martines puso el dicho su decreto. El qual dicho traslado va escrito en estas dichas syete fojas de papel con ésta en que [va] puesto mi signo e van cosidas en uno por pliego entero con filo e en fin de cada plana va pues[to mi] nonbre.

E va escripto sobre raydo o dis sobre e y otro lugar o diz viernes e en otro lugar o dis ha e en otro lugar o dis Palençuela e en otro lugar o dis ves e he, e non enpeesca e fis aquí mio signo.

En testimonio de verdat, Juan Fernandes de Valladolid. (+) 
